\title{
Ensino de História e formação cidadã: um estudo com jovens estudantes em escolas no meio rural e urbano
}

\author{
History teaching and citizen education: a study with \\ young students in rural and urban schools
}

\section{Enseñanza de Historia y formación ciudadana: un estudio con jóvenes estudiantes en escuelas del medio rural y urbano}

\author{
Astrogildo Fernandes da Silva Júnior* \\ Selva Guimarães*
}

\begin{abstract}
Resumo: O estudo tem como objetivo analisar as percepções de jovens estudantes de escolas localizadas no meio rural e urbano sobre política, direitos humanos e cidadania, bem como empreender reflexões sobre desafios e possíveis contribuições do ensino de História para a formação cidadã desses sujeitos. Fizeram parte do universo investigado 130 jovens estudantes dos municípios de Araguari, Uberlândia e Patos Minas, no estado de Minas Gerais, Brasil. Os sujeitos da pesquisa podem ser considerados “jovens pobres" de acordo com o perfil da renda familiar. Concluiu-se que os meios rural e urbano nesses municípios são espaços sociais, econômicos e culturais interdependentes. Em relação à política, a pesquisa corroborou dados internacionais que revelam o desinteresse dos jovens, sendo que os estudantes das escolas do meio rural mostraramse mais céticos do que os jovens urbanos. Em relação aos direitos humanos e à cidadania, prevaleceu o silêncio, principalmente dos jovens das escolas urbanas. $\mathrm{O}$ estudo reafirmou a importância da escola para a formação de uma cultura democrática e participativa, sendo que um dos desafios do professor de História é contribuir para o campo de reflexão e formação dos jovens estudantes acerca das questões políticas, dos direitos humanos e da cidadania.
\end{abstract}

Palavras-chave: Juventudes rural e urbana. Cidadania. Ensino de História.

\begin{abstract}
This study aims to analyze the perception of young students in rural and urban schools on politics, human rights and citizenship, as well as to propose reflections on challenges and possible contributions of history teaching to the citizen education of these individuals. 130 young students from the cities of Araguari, Uberlândia and Patos

\footnotetext{
* Professor da Universidade Federal de Uberlândia - UFU. E-mail: <silvajunior_af@yahoo.com.br>

** Professora do Programa de Pós-Graduação em Educação da Universidade Federal de Uberlândia - UFU. E-mail:<selva@ufu.br>
} 
de Minas in the State of Minas Gerais took part in the study. The research subjects can be considered "poor youngsters" according to their family income. It was concluded that rural and urban environments in these towns are social, economical and cultural independent spaces. In relation to politics, the research corroborated international data which reveal the youngsters' lack of interest, and the rural students were shown more skeptical than the urban ones. Regarding human rights and citizenship, silence was prevalent, mainly amongst the urban young students. The study confirmed the school importance in the formation of a democratic and participant culture, and that one of the challenges to history teachers is to contribute to the field of reflection and education of young students about politics, human rights and citizenship issues.

Keywords: Rural and urban youth. Citizenship. History teaching.

Resumen: El estudio tiene como objetivo analizar las percepciones de jóvenes estudiantes de escuelas rurales y urbanas sobre política, derechos humanos y ciudadanía, así como emprender reflexiones sobre desafíos y posibles contribuciones de la enseñanza de Historia a la formación ciudadana de estos sujetos. Formaron parte del universo investigado 130 jóvenes estudiantes de los municipios de Araguari, Uberlândia y Patos Minas, en el Estado de Minas Gerais, Brasil. A los sujetos de la investigación se les puede considerar "jóvenes pobres" de acuerdo al ingreso familiar. Se concluye que los medios rural y urbano en estos municipios son espacios sociales, económicos y culturales interdependientes. En lo relacionado a la política, la investigación corroboró datos internacionales que revelan el desinterés de los jóvenes, siendo que los estudiantes de las escuelas del medio rural se mostraron más escépticos que los jóvenes urbanos. En lo relacionado a los derechos humanos y a la ciudadanía, prevaleció el silencio, sobre todo entre los jóvenes de las escuelas urbanas. La investigación reafirmó la importancia de la escuela para la formación de una cultura democrática y participativa, siendo que uno de los desafíos del profesor de historia es contribuir en el campo de reflexión y formación de los jóvenes estudiantes acerca de cuestiones políticas, derechos humanos y ciudadanía.

Palabras clave: Juventudes rural y urbana. Ciudadanía. Enseñanza de historia.

\section{Introdução}

De acordo com a Constituição Federal do Brasil, artigo 205 (BRASIL, 1988), a educação é um direito de todos, dever do estado e da família e será promovida e incentivada com a colaboração da sociedade, visando ao pleno desenvolvimento da pessoa, seu preparo para o exercício da cidadania e sua qualificação para o trabalho. Esse princípio vem sendo reiterado nos discursos, de diversas formas, tanto em documentos de políticas públicas quanto nas mídias, principalmente a televisiva. Concordamos com Guido (2007), ao afirmar que quando insiste no mote "educação e cidadania", a sociedade reconhece que ainda carece de fatores vitais da educação e da autêntica e verdadeira cidadania. Nesse contexto de lutas pela conquista e ampliação de direitos básicos para o exercício 
da cidadania, algumas questões nortearam o estudo, dentre elas: qual a percepção dos jovens sobre política, direitos humanos e cidadania? Quais as possibilidades de a História ensinada e aprendida/apreendida contribuir para a formação cidadã dos jovens estudantes?

Neste texto, temos como objetivo compreender e analisar as percepções dos jovens estudantes de escolas localizadas no meio rural e urbano sobre política, direitos humanos e cidadania, bem como refletir sobre desafios e possibilidades do ensino de História contribuir para a formação cidadã desses sujeitos. Inicialmente, apresentamos o percurso metodológico da pesquisa; em seguida, o perfil dos jovens estudantes, sujeitos da investigação, e suas percepções sobre política, direitos humanos e cidadania; finalmente, registramos nossas reflexões sobre os desafios do ensino de História para a formação cidadã.

\section{Opção metodológica, cenário e sujeitos investigados}

A investigação situa-se na abordagem qualitativa de pesquisa educacional, de inspiração etnográfica (GEERTZ, 1978; ANDRÉ, 1995; BOGDAN; BLIKEN, 1991). Busca favorecer uma visão ampla do objeto estudado a partir do envolvimento dos pesquisadores com a realidade social, política, econômica e cultural. Entendemos que a abordagem qualitativa não se resume aos aspectos superficiais e limitados, mas permite considerar e respeitar as subjetividades dos sujeitos da pesquisa.

Nessa perspectiva, utilizamo-nos de vários procedimentos e instrumentos que nos auxiliaram na inserção no campo e na coleta de dados. Realizamos observação participante nas escolas selecionadas, registramos as anotações em diário de campo, relativas às visitas e às observações das aulas de História. Aplicamos um amplo questionário respondido pelos jovens estudantes e realizamos entrevistas orais com professores de História e gestores. Como nos ensina Ginzburg (2007), se a realidade é opaca, existem zonas privilegiadas - sinais, indícios -, que possibilitam decifrá-la, é, pois, necessário examinar os pormenores mais negligenciáveis, basear-se em vestígios imperceptíveis para a maioria.

Fizeram parte do universo investigado 130 jovens estudantes. O cenário da investigação limitou-se aos municípios de Araguari, Uberlândia e Patos Minas, no estado de Minas Gerais, Brasil. Em cada município, escolhemos duas escolas, sendo uma localizada no meio urbano e outra no meio rural, somando o total de seis escolas. O critério da escolha das cidades e das escolas foi resultado de diferentes fatores. Araguari, por ter sido o lócus da nossa experiência pessoal e profissional e objeto de estudo, nos instigou à continuação da pesquisa. Uberlândia, pela grande transformação no padrão produtivo agropecuário, que levou ao esvaziamento e à reconfiguração do meio rural e urbano. Patos de Minas, 
por ter implementado um projeto de escola rural vinculado às especificidades dos habitantes do campo. Em comum, as três cidades têm, no passado, uma forte tradição agrícola.

A primeira etapa da pesquisa, em 2009, consistiu no levantamento das escolas públicas dos municípios investigados e dos jovens estudantes do $9 .^{\circ}$ ano do Ensino Fundamental. Quanto às escolas do município de Araguari, fizemos opção pelas da rede estadual localizadas no campo e da cidade. No meio urbano, nossa pesquisa centrou-se em escolas que possuem localização estratégica, que poderíamos chamar de "rurbanas", ou seja, aquelas situadas na fronteira entre o rural e o urbano, pois recebiam alunos de diversos bairros urbanos e também muitos alunos que residiam em fazendas do entorno da cidade.

Dos municípios de Uberlândia e Patos de Minas, fizeram parte da investigação as escolas municipais. No meio rural de Uberlândia, o lócus da pesquisa foi uma escola que possuía uma grande quantidade de alunos acampados e assentados do Movimento Sem Terra. No meio urbano, selecionamos uma instituição escolar que tinha uma localização estratégica, como descrita anteriormente, logo, atendia a uma diversidade de alunos e alunas, de diversos bairros limítrofes urbanos e de regiões rurais. No meio rural de Patos de Minas, escolhemos uma escola que, segundo gestores da Secretaria de Educação, desenvolvia ativamente o projeto de educação, Edufa/rural ${ }^{2}$, articulado às especificidades e necessidades da população rural. No meio urbano, optamos por uma escola municipal que também atendia a alunos de vários bairros e regiões rurais.

Nossa escolha de estudantes do 9. ${ }^{\circ}$ ano do Ensino Fundamental se deu por múltiplos fatores, tais como o fato de os estudantes desse período fecharem o ciclo curricular da Educação Básica. Alguns alunos encerram os estudos para ingressarem no mercado de trabalho, em particular, os alunos que estudam em escolas no meio rural. Aqueles que continuarem os estudos, precisam mudar-se para as cidades ou deslocar-se, diariamente, para escolas localizadas no meio urbano. Alguns ingressam no Ensino Médio para inserção no Ensino Superior, outros tentarão conciliar a entrada no mercado de trabalho para prover o próprio sustento e a continuação dos estudos. É um período de efervescência na vida, pois várias questões estão em evidência, sobretudo as relativas ao corpo, à sexualidade, ao namoro e às paixões, à política e à sociedade.

\footnotetext{
${ }^{1}$ Para maiores informações sobre o termo "rurbano", ver: Projeto Rurbano, disponível nos sites: <www.eco. unicamp.br> e <www.neard.org.br>. Acesso em: 20 out. 2011.

${ }^{2}$ O Município de Patos de Minas promoveu, no período de 2001 a 2004, um programa de desenvolvimento sustentável, mais especificamente, o Projeto de Educação Família Rural (Edufa/rural). O projeto fundou-se no referencial de educação de Paulo Freire, cujas bases conceituais e estratégias pedagógicas visavam à valorização das identidades do homem e da mulher do campo. O ponto de partida foi o contexto natural, social e econômico do aluno, sua vivência cotidiana e sua cultura. Atualmente, funciona como uma disciplina com uma aula semanal em cada turma do Ensino Fundamental das escolas localizadas no meio rural do município.
} 
Nossa proposta consistiu na observação participante do cotidiano escolar, especificadamente, de aulas de História, do último ano do Ensino Fundamental. Aplicamos um questionário, que foi respondido pelos 130 jovens estudantes, de diferentes turmas. Esse instrumento teve como objetivo capturar o perfil, o pensamento, as ideias e caracterizar a diversidade dos sujeitos (jovens estudantes). Para sistematizar os dados, utilizamos o programa Statistical Package for Social Sciences - SPSS, que proporciona um tratamento estatístico dos dados. Como anunciamos anteriormente, neste texto, apresentaremos análises sobre as percepções dos jovens estudantes de escolas do meio rural e urbano sobre política, direitos humanos e cidadania, bem como reflexões sobre os desafios do ensino de História na formação cidadã. Assim, utilizamos parte dos resultados dos questionários e os registros das notas de campo produzidas ao longo da observação participante.

\section{Percepções dos jovens estudantes: política, direitos humanos e cidadania}

Este tema tem sido objeto de várias pesquisas. Para Abramo e Branco (2005, p. 37), "muito do que se escreve sobre juventude é para alertar para os deslizes, os encobertamentos, as disparidades e mistificações que o conceito encerra". Carneiro (2005) afirma que o termo juventude remete a uma série de definições divergentes. Culturalmente determinada, a demarcação dessa etapa da vida é sempre imprecisa, sempre referida ao fim dos estudos, ao início da vida profissional, à saída da casa paterna ou à constituição de uma nova família ou, simplesmente, uma faixa etária.

Em relação aos jovens que vivem no meio rural, é comum, na literatura, o uso da categoria "juventude rural", embora o nosso contato com os jovens investigados nos permita afirmar que eles não se identificam com essa conceituação. Segundo Marin (2010), a juventude rural é uma invenção da sociedade industrial. É uma construção sociocultural que começou a se estabelecer nas últimas décadas do século XIX e se consolidou apenas no século XX, nas sociedades industrializadas. Posteriormente, com a industrialização tardia dos países latino-americanos e sua correlata modernização da agricultura, a ideia de juventude rural foi inserida nos discursos e nas práticas das instituições desenvolvimentistas.

Sposito (1997) entende que seria quase impossível recorrer ao uso da categoria "jovem" de modo igual. A autora considera "juventude" como uma categoria socialmente constituída, que atende a fenômenos existentes, possui uma dimensão simbólica, mas que também deve ser analisada a partir de outras dimensões: materiais, históricas e políticas, nas quais todas as produções sociais 
se desenvolvem. Concordamos com Abramo e Branco (2005), ao tratar de "juventudes" no plural e não de "juventude" no singular, para não esquecer as diferenças e desigualdades que atravessam essa condição. De acordo com Novaes (2006), o conceito de juventude tem mudado no tempo e é sempre diferente nas diversas culturas e espaços sociais. Em nossa pesquisa, o perfil dos jovens pode ser configurado da seguinte maneira: de um total de 130 jovens estudantes, $55,5 \%$ estudavam em escolas no meio urbano e $45,5 \%$ no meio rural. A maior parte dos entrevistados se declarou branco, 49,3\%; e 5,4\% declararam-se pretos e $35,4 \%$ pardos.

Quanto ao trabalho, entendido como fonte de renda, trabalho assalariado e não como trabalho laboral, que é recorrente, principalmente, entre os jovens do campo, $100 \%$ dos entrevistados não possuía trabalho formal. Porém, muitos faziam parte do que Silva Blass (2006) denomina mercado de trabalho clandestino ou subterrâneo, predefinido de um ponto de vista estritamente econômico como precário. Quando interrogados se estavam trabalhando, obtivemos os seguintes números:

Tabela 1 - A inserção no mundo do trabalho dos jovens da pesquisa

\begin{tabular}{l|c|c}
\hline & Jovens do meio rural & Jovens do meio urbano \\
\hline Está trabalhando & $17,6 \%$ & $25,3 \%$ \\
\hline Nunca trabalhou & $50,4 \%$ & $47,0 \%$ \\
\hline $\begin{array}{l}\text { Nunca trabalhou, mas está } \\
\text { procurando trabalho }\end{array}$ & $17,7 \%$ & $18,7 \%$ \\
\hline Já trabalhou e está desempregado & $14,3 \%$ & $9,0 \%$ \\
\hline Total & $100,0 \%$ & $100,0 \%$ \\
\hline
\end{tabular}

Fonte: Os autores.

Se considerarmos que os jovens colaboradores desta investigação eram estudantes do 9. ${ }^{\circ}$ ano do Ensino Fundamental, portanto, com a média de idade de 14-15 anos, a tabela revela um alto percentual de jovens, tanto do campo quanto da cidade, que estava trabalhando ou procurando trabalho. É uma informação preocupante, pois estes jovens deveriam estar se dedicando plenamente à formação. Lembramos que o trabalho é proibido no Brasil para crianças e adolescentes até 14 anos de idade. Entre 14 e 16 anos, é permitido apenas na condição de aprendiz que deve frequentar a escola regular.

A renda familiar da maioria dos jovens colaboradores desta pesquisa atingia no máximo cinco salários mínimos. Podemos considerá-los “jovens pobres". No meio rural, a situação se agravava, pois $42,5 \%$ afirmaram que essa renda era entre um até dois salários mínimos. Como em todo o Brasil, a renda familiar média dos trabalhadores rurais é menor que a dos trabalhadores urbanos, 
conforme os indicadores sociais do IBGE. Ainda prevalece a condição histórica do trabalhador rural, no Brasil, denunciada por Wanderley (2010). Segundo a autora, o trabalhador rural vive submetido às distintas formas de dominação, de concentração da propriedade da terra e do capital.

Outra questão abordada para desenhar o perfil dos jovens em nossa investigação foi a religião. Para Novaes (2005), a religião pode ser vista como um dos aspectos que compõem o mosaico da grande diversidade da juventude brasileira. A religião católica continua sendo predominante entre os jovens do campo e da cidade. Registramos um percentual maior de católicos entre os jovens estudantes das escolas rurais, 79,5\%, enquanto $58,3 \%$ dos jovens estudantes das escolas urbanas declararam-se católicos. O número de evangélicos é maior entre os jovens da cidade, $24,1 \%$, e no meio rural, $8,5 \%$. Outro fator que nos chamou a atenção é que, seguido aos evangélicos, 9,6\% dos jovens do meio rural e 10,0\% dos jovens da cidade se declararam "sem religião". Verificamos que, para a maioria dos jovens estudantes, tanto das escolas localizadas no meio rural quanto no meio urbano, a religião significava muito em suas vidas. Fato que nos permite concordar com Modesto (1996), ao assegurar que a religião passa por uma renovação nos nossos dias e permanece como uma das forças atuantes no campo da formação humana. Dessa forma, interfere na constituição das identidades dos jovens estudantes.

Quanto à questão política, corroboramos Krischke (2005), ao afirmar que a importância dos estudos sobre cultura política está nas evidências que eles podem proporcionar a respeito da disposição das pessoas em apoiar o regime democrático, apesar das eventuais desilusões acerca de um ou de outro partido ou governante.

A análise das notas de campo revela indícios do descaso, do desinteresse dos jovens com a política, corroborando pesquisas internacionais (SANTISTEBAN; PAGÈS, 2007). É exemplar o fato de que apenas seis meses antes da eleição presidencial no Brasil de 2010, alguns estudantes não sabiam dizer quem era Dilma Rousseff. As marcas de nosso tempo reforçam a decadência da popularidade do engajamento político em que o espaço público, segundo Bauman (2001), está cada vez mais vazio de questões públicas. Isso serve de alerta para educadores e representantes políticos. Este pode ser mais um desafio: incentivar a formação e a participação política dos jovens brasileiros.

De acordo com Krischke (2005), o ingresso dos jovens no eleitorado e na atividade produtiva manifesta uma renovação demográfica constante, que, às vezes, pode desafiar o conjunto da população e das instituições que devem reger o presente e o futuro do país. Nesse sentido, questionamos aos jovens colaboradores: Você diria que o que acontece na politica influi ou não na sua vida? 
Constatamos que os jovens estudantes das escolas urbanas acreditam mais na influência política em suas vidas, $40,6 \%$ disseram que a política influi muito, enquanto $38,8 \%$ dos jovens das escolas do meio rural compartilham dessa afirmação. Ao modificarmos a pergunta, invertendo a situação, ou seja, E você influi ou não na politica? A maioria dos jovens das escolas rurais, $56,9 \%$ e $53,7 \%$ dos jovens das escolas urbanas declarou que não influenciam na política. Os dados indicam desapontamentos em relação à política. Ao longo das observações, presenciamos diálogos entre os jovens sobre como percebem a política e, na maioria das vezes, destacam a corrupção e o descrédito relacionados à política brasileira.

Ficamos instigados em conhecer a opinião dos jovens colaboradores sobre seus posicionamentos políticos. Sugerimos três frases e pedimos que assinalassem a alternativa que melhor representava seu pensamento. Apresentamos os dados na tabela 2:

Tabela 2 - Frase que representa o pensamento sobre política para os jovens

\begin{tabular}{l|c|c}
\hline & Jovens do meio rural & Jovens do meio urbano \\
\hline $\begin{array}{l}\text { A democracia é sempre a me- } \\
\text { lhor forma de governo. }\end{array}$ & $39,5 \%$ & $32,0 \%$ \\
\hline $\begin{array}{l}\text { Em certas situações, é melhor } \\
\text { uma ditadura do que demo- } \\
\text { cracia. }\end{array}$ & $6,0 \%$ & $15,2 \%$ \\
\hline $\begin{array}{l}\text { Tanto faz se o governo é de- } \\
\text { mocracia ou ditadura. }\end{array}$ & $9,9 \%$ & $13,2 \%$ \\
\hline Não sei. Total & $44,6 \%$ & $39,5 \%$ \\
\hline \multicolumn{1}{c}{$\quad 100,0 \%$} & $100,0 \%$ \\
\hline
\end{tabular}

Fonte: Os autores.

Valemo-nos da comparação entre os jovens estudantes em escolas do meio urbano e no meio rural, todos os alunos cursavam o 9. ${ }^{\circ}$ ano do Ensino Fundamental e se aproximavam no que se refere à renda. Os dados da tabela 2 revelam que $39,5 \%$ dos jovens do campo e 32,0\% dos jovens da cidade defendiam a democracia como melhor forma de governo, ou seja, uma porcentagem menor, se considerada com a média nacional, 43\%, apurada em 2005 por Krischke. A maior parte dos jovens colaboradores desta investigação não soube opinar.

O desinteresse, a indiferença e o desconhecimento de questões ligadas à política são sinais de atitudes apolíticas, é o que Krischke (2005) denomina de apoliticismo. Com o intuito de aprofundar a investigação sobre a cultura política dos jovens colaboradores, questionamos sobre a importância ou não do vários partidos políticos existentes no Brasil. Registramos os dados na tabela 3. 
Tabela 3 - Opinião dos jovens sobre os partidos políticos

\begin{tabular}{l|c|c}
\hline & Jovens do meio rural & Jovens do meio urbano \\
\hline $\begin{array}{l}\text { É bom para o Brasil ter muitos } \\
\text { partidos como tem hoje. }\end{array}$ & $19,1 \%$ & $20,6 \%$ \\
\hline $\begin{array}{l}\text { Seria melhor ter vários partidos, } \\
\text { mas menos do que tem hoje. }\end{array}$ & $19,6 \%$ & $29,9 \%$ \\
\hline $\begin{array}{l}\text { Seria melhor se tivesse um único } \\
\text { partido. }\end{array}$ & $21,1 \%$ & $14,7 \%$ \\
\hline $\begin{array}{l}\text { Seria melhor se não tivesse } \\
\text { partido nenhum. }\end{array}$ & $10,1 \%$ & $13,2 \%$ \\
\hline Não sei. Total & $30,1 \%$ & $21,6 \%$ \\
\hline \multicolumn{1}{c}{ Tal } & $100,0 \%$ & $100,0 \%$ \\
\hline
\end{tabular}

Fonte: Os autores.

A análise revela um alto percentual de jovens que não sabem opinar sobre os partidos políticos. O índice é ainda maior, se considerarmos os jovens do campo. A maioria avaliou os partidos políticos como pouco importantes. Os dados revelam o desconhecimento das formas de governo, a falta de formação política e participação cidadã, além de exporem sinais de ceticismo dos jovens em relação às instituições políticas.

Tudo parece indicar que a apatia dos jovens ante a política tem relação com a desilusão que se refere a esta instituição, que, cada vez mais, está ligada a graves problemas relacionados à corrupção e à falta de transparência e eficácia na gestão. Outra hipótese que pode ajudar a explicar o fenômeno é a contribuição da escola para o desenvolvimento de habilidades e de estratégias essenciais para a democracia.

Citamos algumas instituições, como: familia; professores; igrejas e padres católicos; outros parentes; companheiros de trabalho; militares das Forças Armadas; movimentos populares; colegas de escola; igreja e pastores evangélicos; Polícia Militar; Polícia Civil; Juízes dos tribunais de Justiça; Movimentos dos sem-terra; promotores e procuradores do Ministério Público; Movimento sindical; Governo Federal; empresários; vereadores da sua cidade; partidos políticos; deputados e senadores do Congresso Nacional. Questionamos acerca das instituições e grupos nas quais confiavam. Exibimos os números na tabela 4: 
Tabela 4 - Instituições para as quais os jovens expressam confiança

\begin{tabular}{l|c|c}
\hline & $\begin{array}{c}\text { Jovens do meio } \\
\text { rural }\end{array}$ & $\begin{array}{c}\text { Jovens do meio } \\
\text { urbano }\end{array}$ \\
\hline Família & $85,6 \%$ & $98,0 \%$ \\
\hline Professores & $81,6 \%$ & $76,6 \%$ \\
\hline Igrejas e padres católicos & $66,7 \%$ & $66,9 \%$ \\
\hline Militares das Forças Armadas & $43,6 \%$ & $60,5 \%$ \\
\hline Movimentos Populares & $37,5 \%$ & $48,0 \%$ \\
\hline Colegas da escola & $82,5 \%$ & $72,4 \%$ \\
\hline Igrejas e pastores evangélicos & $35,0 \%$ & $51,4 \%$ \\
\hline Polícia Militar & $32,8 \%$ & $67,4 \%$ \\
\hline Polícia Civil & $49,1 \%$ & $64,9 \%$ \\
\hline Juízes do Tribunal de Justiça & $51,7 \%$ & $67,7 \%$ \\
\hline Movimento dos sem terra & $21,6 \%$ & $28,5 \%$ \\
\hline Promotores e procuradores do Ministério Público & $31,5 \%$ & $44,1 \%$ \\
\hline Governo Federal & $16,2 \%$ & $41,4 \%$ \\
\hline Vereadores da Cidade & $19,7 \%$ & $33,5 \%$ \\
\hline Movimento Sindical & $25,2 \%$ & $52,7 \%$ \\
\hline Deputados e Senadores do Congresso Nacional & $14,9 \%$ & $19,3 \%$ \\
\hline
\end{tabular}

Fonte: Os autores.

A instituição que obteve o maior percentual de confiança, tanto dos jovens do campo quanto da cidade, foi a família, seguida pelos professores, colegas da escola e padres católicos. Com exceção dos itens professores e colegas da escola, a tabela evidencia que os jovens do campo acreditam menos nas outras instituições. Os dados nos permitem confirmar a descrença dos jovens colaboradores em relação às instituições políticas. É mais alarmante, se levarmos em conta apenas os jovens do campo. São indícios de que as políticas públicas chegam pouco até os jovens e menos ainda aos jovens que vivem no meio rural.

No entanto, a maior parte dos jovens colaboradores desta investigação acredita que pode mudar o mundo. $56,4 \%$ dos jovens do meio rural e $62,1 \%$ dos jovens da cidade afirmaram que podem mudar muito.

Questionamos os jovens colaboradores sobre se, num passe de mágica, pudessem mudar qualquer coisa na vida ou no mundo, qual seria a primeira coisa que fariam?, a maioria dos jovens das escolas localizadas no meio rural, 53,1\%, acabaria com a violência. A maior parte dos jovens das escolas do meio urbano, 42,8\%, acabaria com a miséria. A análise nos remete às condições socioeconômicas; nível de renda e consciência sobre os problemas citados. Mais uma vez, podemos perceber que a violência não é privilégio do meio urbano, mas é frequente no meio rural. Como afirma Novaes (2006), o medo de sobrar e o medo de morrer revelam as preocupações dos jovens com a violência e o desemprego, num mundo marcado 
pela insegurança nas grandes cidades, cidades de médio porte e também no meio rural e um mercado de trabalho restrito e em mudança.

Também perguntamos aos jovens sobre quais seriam os valores mais importantes para uma sociedade ideal:

Tabela 5 - Valores que os jovens consideram mais importantes para a sociedade

\begin{tabular}{l|c|c}
\hline & Jovens do meio rural & Jovens do meio urbano \\
\hline $\begin{array}{l}\text { Solidariedade; respeito às diferenças; } \\
\text { respeito ao meio ambiente }\end{array}$ & $72,2 \%$ & $69,1 \%$ \\
\hline $\begin{array}{l}\text { Respeito às diferenças; respeito ao } \\
\text { meio ambiente; temor a Deus }\end{array}$ & $16,4 \%$ & $22,2 \%$ \\
\hline $\begin{array}{l}\text { Solidariedade; igualdade; respeito ao } \\
\text { meio ambiente }\end{array}$ & $11,4 \%$ & $8,7 \%$ \\
\hline \multicolumn{1}{c}{ Total } & $100,0 \%$ & $100,0 \%$ \\
\hline
\end{tabular}

Fonte: Os autores.

Os valores considerados pelos jovens, tanto do meio rural quanto urbano, como mais importantes para a sociedade são: solidariedade; respeito às diferenças; respeito ao meio ambiente. A ênfase na solidariedade corrobora os dados da pesquisa do Projeto Juventude. De acordo com Singer (2005), os jovens brasileiros estão em sintonia com os valores dos jovens de vários países.

A ênfase na solidariedade como valor mais citado chama-nos a atenção para a existência de valores relacionados à noção de cidadania entre esses jovens. São dados que contrastam tanto com o estereótipo do jovem, como "individualista" e "descomprometido com os problemas sociais", como com a imagem, geralmente associada aos habitantes do campo, como "atrasados", "ignorantes" e "voltados para seus interesses próprios". Outro destaque foi o respeito ao meio ambiente, o que sugere uma consciência ecológica expressiva entre os jovens.

Conforme o artigo $1^{\circ}$ da Declaração Universal dos Direitos Humanos, "todos os homens nascem livres e iguais em dignidade e direitos. São dotados de razão e consciência e devem agir em relação uns aos outros com espírito de fraternidade". É, inclusive, recorrente nos documentos oficiais, tais como a Constituição Federal de 1988 e a Lei de Diretrizes e Bases da Educação Básica 9.394/96 -, o respeito aos direitos humanos e à formação de uma nova cidadania. Arguimos os jovens estudantes sobre o que pensam ao falar em cidadania: 
Tabela 6 - O que os jovens relacionam com o conceito de cidadania

\begin{tabular}{l|c|c}
\hline & Jovens do meio rural & Jovens do meio urbano \\
\hline Direitos e responsabilidades & $7,3 \%$ & $8,1 \%$ \\
\hline Respeito ao meio ambiente & $1,2 \%$ & $2,3 \%$ \\
\hline Amizade & $7,8 \%$ & $2,4 \%$ \\
\hline Ser cidadão de bem & $5,4 \%$ & $20,9 \%$ \\
\hline Igualdade e liberdade para todos & $9,7 \%$ & $4,8 \%$ \\
\hline Ter direitos & $9,1 \%$ & $12,8 \%$ \\
\hline Solidariedade & $14,6 \%$ & $4,9 \%$ \\
\hline Respeito entre as pessoas & $6,0 \%$ & $8,8 \%$ \\
\hline Educação & $6,5 \%$ & $1,2 \%$ \\
\hline Não sei & $32,4 \%$ & $33,8 \%$ \\
\hline
\end{tabular}

Fonte: Os autores.

Para a resposta dessa questão, não oferecemos alternativas, foi uma questão aberta. Como observamos na tabela $6,32,4 \%$ dos jovens do meio rural e $33,8 \%$ dos jovens do meio urbano não souberam responder. A ausência de respostas, bem como as respostas apresentadas nos revelam que um dos desafios das escolas, tanto do meio rural quanto do meio urbano dos municípios investigados, é dialogar com os jovens estudantes sobre os direitos humanos e cidadania. Além disso, reforça a necessidade de políticas públicas que tenham como foco a formação cidadã.

Em outra questão, também aberta, pedimos para que os colaboradores citassem dois direitos que considerassem mais importantes.

Mais uma vez, grande parte dos entrevistados, principalmente do meio urbano, especificamente 19,5\% dos jovens das escolas rurais e 31,8\% dos jovens das escolas urbanas, afirmaram não saber quais os direitos consideram mais importantes. A resposta espontânea indicou que 35,6\% dos jovens rurais e 26,3\% dos jovens urbanos sugeriram os direitos individuais, liberdade, igualdade, respeito, seguido de direitos sociais, 12,3\%, educação, saúde. Evidenciamos que os jovens do campo foram mais participativos, registrando os direitos que avaliaram como mais importantes. Acreditamos que os destaques têm relação com a carência, ou seja, destacam aquilo que falta.

Pedimos para que criassem direitos que não existem no papel. Muitos jovens se omitiram. 31,7\% dos jovens das escolas rurais e 50,6\% dos jovens das escolas urbanas não responderam à questão. Quanto aos que responderam, evidenciamos que, se pudessem, criariam direitos para beneficiá-los, como, por exemplo, tirar carteira de motorista aos 16 anos; entrar em boates; trabalho etc.

De acordo com Portinari e Coutinho (2006), ser jovem, na cultura ocidental contemporânea, é, sobretudo, uma forma de identidade, um estilo de vida. 
Os jovens sentem necessidade de participar de um grupo, de se integrar à sociedade de consumo. Muitas vezes, não se enquadravam em determinados grupos. Perguntamos aos entrevistados se já se sentiram humilhados, desrespeitados ou discriminados por qualquer motivo. 66,3\% dos jovens estudantes das escolas localizadas no meio rural e 59,4\% de jovens das escolas localizadas no meio urbano sofreram algum tipo de discriminação.

Os motivos da discriminação foram os mais variados: pela cor da pele, religião, moradia, estética, idade etc. Muitos preferiram não comentar, o que evidencia o quanto ainda se sentem incomodados pelo fato de terem sido discriminados. Sabemos que o Brasil foi construído com uma base multicultural muito forte. Segundo Candau (2002), as relações interétnicas têm sido uma constante ao longo da nossa história, uma história dolorosa, notadamente para os grupos indígenas e afrodescendentes.

Para efetivar uma educação multicultural, Sacristán (1995) nos alerta que não basta introduzir alguns temas a mais. Para o autor, um currículo multicultural implica mudar não somente as intenções do que queremos transmitir, mas os processos internos que são desenvolvidos na educação institucionalizada. À medida que a educação escolarizada não intervier na crítica e depuração desse conhecimento social extraescolar, ela não se tornará ativa em um âmbito de socialização, decisivo para os indivíduos. Segundo Sacristán (1995, p. 90-91),

Ressaltar o valor e a força do currículo extraescolar deve servir para os educadores moderarem as expectativas de seu poder de intervenção a partir da escola, fazendo com que a perspectiva multicultural seja formulada a partir de coordenadas mais amplas que as do currículo escolar, com frentes de atuação muito diversas, e com que se proponham estratégias didáticas que vinculem o conhecimento escolar relativo ao tema que nos ocupa com as aprendizagens de origem externa à escolaridade.

Defendemos a importância de "empoderar" os jovens estudantes de forma que se percebam como importantes sujeitos de direitos, protagonistas sociais, para que possam atuar no mundo social, cientes de suas potencialidades, de seus direitos e de seu poder. Enfim, possibilitar que os alunos adquiram habilidades, conhecimentos para conviverem, valorizarem e respeitarem os diferentes grupos e etnias de nossa sociedade plural.

O estudo levou-nos a compreender que a construção das identidades ocorre durante toda a vida, trata-se de um processo dinâmico de transformação, em que são evidentes as marcas das novas tecnologias de informação e comunicação. Os jovens estudantes revelaram olhares críticos em relação ao rádio e à televisão, por exemplo. Assim, é necessário que o professor busque maneiras de inseri-los, de 
forma crítica, no seu cotidiano pedagógico, no sentido de busca do senso crítico e de capacidade de análise da presença intensa das mídias na nossa vida.

Os caminhos da nossa investigação nos levam à constatação de que os jovens que chegam às escolas públicas, tanto do meio rural quanto do meio urbano dos municípios investigados, são diversos, plurais, produto de experiências de socialização em contextos sociais múltiplos. As diferentes dimensões da condição juvenil são profundamente marcadas pelo espaço onde são construídas. Concordamos com Dayrell (2003), ao afirmar que a construção do conceito de juventude desprovida de fixidez de critérios e imagens fragmentadas é essencial para se preservar a perspectiva da diversidade. Consideramos que trabalhar com as diferenças, com o espaço multicultural e, assim, contribuir para formação cidadã, é mais um desafio do ensino de História, tanto nas escolas do meio rural quanto no meio urbano. Na continuação deste texto, buscamos compreender o ensino de História nas escolas investigadas e refletir sobre as potencialidades para a formação cidadã dos jovens estudantes.

\section{Reflexões sobre o ensino e aprendizagem de História e a formação cidadã}

A atual configuração da educação escolar é resultante de múltiplos fatores, dentre eles, dos caminhos da democratização do país a partir dos anos de 1970, caracterizados progressivamente, por uma série de transformações. No processo de migração, o fluxo de pessoas se tornou intenso, tanto do meio rural para as cidades, como também entre os estados e países. O espaço escolar tornou-se cada vez mais complexo e multicultural com a progressiva democratização do acesso. As tecnologias de comunicação, particularmente o rádio e a televisão, expandiram-se consideravelmente. Essa nova realidade não pôde mais ser ignorada pela escola. As propostas curriculares passaram a expressar o debate entre as diversas tendências da pesquisa historiográfica e educacional. Segundo Cerri (2011), no que se refere à especificidade do ensino de História, os anos de 1980 e boa parte da década de 1990 foram marcados por tentativas, de professores e intelectuais, de formular propostas que congregassem a nova identidade a formar junto aos alunos: nacional, mas também socialmente crítica. Avaliavam ser imperativo revisar a história dos vencedores e abrir espaço para outras histórias, como a dos vencidos. Destacavam a importância de trazer o homem e a mulher comuns para a sala de aula e convencê-los do protagonismo essencial do povo nos processos históricos.

Temas ligados à história social, cultural e do cotidiano passaram a ser, gradativamente, mais incorporados. $\mathrm{O}$ debate gerou reavaliações do ensino de História ilustrado por múltiplas abordagens. Difundiram-se reflexões sobre o 
processo de ensino e aprendizagem, segundo as quais os alunos são considerados sujeitos de saberes, participantes ativos do processo de conhecimento. Assim, nesse âmbito, os métodos tradicionais de ensino, como memorização e reprodução, passaram a ser questionados.

O que temos de concreto, no espaço escolar no cenário atual, é uma diversidade de sujeitos, são homens, mulheres, negros, brancos, homo e heterossexuais, de diversas regiões do país, ou seja, um espaço plural no qual convivem diversas identidades. Para Bauman (2005), é uma fantasia acreditar em uma identidade totalmente unificada, completa, segura e coerente. Temos um sujeito fragmentado, cambiante, deslocado, no qual estão em conflitos várias identidades, algumas, inclusive, antagônicas. Nesse sentido, os processos identitários dependem de escolhas, esforços, negociações, lutas, entendimento, desentendimentos, muitas vezes, perturbadores e desconfortáveis. Para Hall (1999), vivemos em um contexto marcado pela fluidez e interpenetração entre diversos pertencimentos e condições, o que anuvia a identidade coletiva, cada vez mais estilhaçada. Nesse cenário, Cerri (2011) assevera que o político tende a ser mais pessoal, e o espaço público se esvazia como campo de definição de destinos, prevalece, cada vez mais, a resolução de questões pessoais que não afetam decisivamente a estrutura social. O autor, inclusive, registra sua crítica ao Movimento dos Sem Terra, que, segundo ele, saudado pela esquerda como saída para o marasmo das lutas populares, tem por efeito principal, quando bem-sucedido em suas jornadas, multiplicar a quantidade de pequenos proprietários rurais, que ganham o direito de frequentar o mercado capitalista de cabeça erguida (CERRI, 2011, p. 109).

[...] No que se refere à contribuição para a vida do sujeito, sua função é alargar horizontes e permitir a ascensão de forma mais complexas de pensamento, além de preparar a "autodefesa intelectual" (essa expressão é de Noam Chomsky), ou seja, ajudar no sentido de que o cidadão não seja suscetível a manipulações que o subjuguem a interesses alheios. Além disso, deve contribuir para que os futuros cidadãos não fiquem presos no "presente contínuo", que acabará por ter características entrópicas ou destrutivas para a sociedade. Nesse conjunto de tarefas, o ensino de história participa do trabalho socializador da escola tirando o sujeito do egocentrismo e introduzindo-o na vida pública, com o que nos confrontamos com o individualismo e o esvaziamento do espaço público que vivenciamos. (CERRI, 2011, p. 112-113).

Perguntamos aos jovens estudantes, colaboradores de nossa investigação, sobre possíveis significados da disciplina. As respostas revelaram que a maioria dos jovens possui representações positivas da História. Em relação aos jovens das escolas do meio rural, destacou-se a afirmação de que a História é uma fonte de aventura que estimula a imaginação $(24,7 \%)$ e, para os jovens das escolas do meio urbano, mostrou-se o que está por detrás dos modos de vida do presente, $(41,5 \%)$. 
Perguntamos aos jovens sobre o que mais valorizavam no estudo da História: o conhecimento do passado? A compreensão do presente? A orientação para o futuro? Ou as três situações? Do total dos sujeitos investigados, 58,47\% responderam que é, ao mesmo tempo, conbecimento do passado, do presente e orientação para o futuro. Os jovens das escolas localizadas no meio rural foram os que mais acreditam na articulação entre os três tempos, $65,0 \%$ assinalaram essa opção.

Para Pais (1999), as origens das coisas presentes e futuras encontram-se no passado ou, em outros termos, a melhor maneira de compreender uma realidade é conhecer-lhe as pegadas, pois a incompreensão do presente e do futuro nasce da ignorância do passado. Na mesma perspectiva, Rusen (2001) afirma que a compreensão do presente e a projeção do futuro somente são possíveis com a recuperação do passado. Daí a importância do professor investigar como os alunos pensam o passado, pois acreditamos que o passado está presente no aluno de forma prática ou encapsulado.

Para Cerri (2011), Rusen (2007), não é suficiente conhecer fatos e processos históricos, é fundamental ter a capacidade de interpretar o tempo e usar esse conhecimento para a própria vida, agindo em conformidade com os próprios princípios e objetivos. O que denota que a História deve ter relação com a vida prática. Segundo Alegro (2007), aprender em História é uma construção em torno daquilo que o professor e o estudante trazem para a sala de aula e dos significados que trocam em relação ao conteúdo da disciplina. Para Schimidt; Barca e Garcia (2010), a aprendizagem em História deve ser significativa em termos pessoais e, desse modo, proporcionar aos estudantes uma compreensão mais profunda da vida humana. Nesse sentido, acreditamos que as diferentes linguagens da cultura contemporânea podem auxiliar o ensino de História nessa tarefa, ou seja, contribuir para o "letramento histórico". Questionamos, então, aos jovens estudantes que tipos de fontes históricas mais lhes agradam? E quais as em que mais confiam? Os estudantes poderiam escolher até três fontes. Registramos os dados respectivamente nas tabelas 7 e 8 :

Tabela 7 - Fontes de História que mais agradavam aos jovens

\begin{tabular}{l|c|c}
\hline & Jovens do meio rural & Jovens do meio urbano \\
\hline Museus & $83,4 \%$ & $66,5 \%$ \\
\hline Filmes de ficção & $57,3 \%$ & $47,4 \%$ \\
\hline Documentos & $40,2 \%$ & $40,6 \%$ \\
\hline Livros escolares & $17,9 \%$ & $15,7 \%$ \\
\hline Romances históricos & $13,2 \%$ & $18,7 \%$ \\
\hline Narrativas de professores & $8,6 \%$ & $17,5 \%$ \\
\hline Narrativas de adultos & $17,5 \%$ & $6,3 \%$ \\
\hline Documentos televisivos & $4,3 \%$ & $8,1 \%$ \\
\hline
\end{tabular}

Fonte: Os autores. 
Tabela 8 - Fontes de História em que os jovens mais confiam

\begin{tabular}{l|c|c}
\hline & Jovens do meio rural & Jovens do meio urbano \\
\hline Museus & $69,1 \%$ & $72,8 \%$ \\
\hline Documentos & $56,5 \%$ & $50,7 \%$ \\
\hline Narrativas de professores & $36,1 \%$ & $41,9 \%$ \\
\hline Livros escolares & $40,6 \%$ & $27,8 \%$ \\
\hline Filmes de ficção & $8,4 \%$ & $15,2 \%$ \\
\hline Narrativas de adultos & $16,2 \%$ & $5,6 \%$ \\
\hline Romances históricos & $2,5 \%$ & $3,7 \%$ \\
\hline Documentos televisivos & - & $2,4 \%$ \\
\hline
\end{tabular}

Fonte: Os autores.

A ênfase dada aos museus, como uma das principais fontes de aprendizagem e que inspira confiança, pode ser compreendida pelo desejo de conhecer um museu, ou seja, muitos constroem uma representação positiva de um espaço que ainda não conhecem fisicamente. Esse pode ser um elemento potencializador para o uso da cultura material no ensino de História. De acordo com Silva e Fonseca (2007), a cultura material, associada às outras problemáticas de conhecimento histórico, encontra múltiplos itens para a reflexão em museus visitados pessoal ou virtualmente. Os autores alertam que quando se fala de cultura material, a primeira imagem que se forma é a do mundo dos objetos fisicamente palpáveis, o que não é um erro, mas pode conduzir a equívocos, como o de supor que a cultura material se encerra ali. Lembram-nos de que os objetos não são simples "coisas", uma vez que fazem parte dos fazeres humanos, englobam saberes, aprendizados, ensinamentos e simbologias de várias naturezas. Dessa forma, opor a cultura material à outra cultura "imaterial" é perder de vista imperativos humanos que percorrem todas as práticas culturais.

Por meio das respostas dos jovens estudantes, percebemos que os filmes são considerados fontes favoritas de aprendizagem da História. No entanto, esse gosto não se traduz em confiança. Isso nos instiga a refletir sobre como o filme está sendo utilizado na sala de aula. Bittencourt (2005) alerta para a não banalização dessa importante fonte. Os filmes, numa perspectiva interdisciplinar, possibilitam a abordagem e o debate de diferentes temas. É preciso ter claros os limites próprios da linguagem, não reduzindo a mera ilustração, nem tampouco exigindo dela a transmissão objetiva e sistematizada de determinado conteúdo.

Se, por um lado, os livros didáticos e as narrativas dos professores não representam as fontes que mais lhes agradam, por outro, são aquelas que inspiram confiança. De acordo com Bittencourt (2005), os livros didáticos, analisados com maior profundidade e em perspectiva histórica, demonstram ter sofrido mudanças em seus aspectos formais e ganharam possibilidades de 
usos diferenciados. Silva e Fonseca (2010) defendem que os livros didáticos, em sala de aula, precisam ser ampliados, complementados, criticados, revistos. O professor deve ter uma relação crítica, nunca de submissão ao livro de História, que, como todo texto, toda fonte, merece ser questionado, problematizado e amplamente explorado com os alunos. Rusen (2010) ressalta que o bom livro didático deve apresentar quatro características: um formato claro e estruturado; uma estrutura didática clara; uma relação produtiva com o aluno e uma relação com a prática da aula.

Comungamos com Pagès (2011), ao afirmar que aprender História pode ser uma arma para a liberdade e para a formação de uma cidadania livre e solidária. O ensino de História pode permitir aos jovens estudantes desenvolver um sentido de identidade e respeito. Sendo assim, propicia conhecimentos necessários para a educação cidadã. Para isso, o autor sugere mudanças na concepção do saber histórico escolar, tais como: problematizar os conteúdos históricos escolares; potencializar mais o ensino do século XX; fomentar os estudos comparativos; evitar enfoques nacionais excessivamente centralistas; conceder maior protagonismo aos homens e mulheres que aos territórios.

Nessa perspectiva, acreditamos ser de extrema importância a diversificação de fontes e linguagens no processo de ensino e aprendizagem. O professor, ao ensinar História, pode incorporar as noções transmitidas nos diversos espaços e meios de comunicação, nos grupos de vivência fora da escola, na família, nos espaços de lazer etc. A formação do aluno/cidadão se inicia e processa nos diversos espaços de vivência. Logo, devemos considerar como fontes do ensino de História todos os veículos e materiais que contribuam para a difusão do conhecimento, responsável pela formação do pensamento crítico: os meios de comunicação de massa, rádio, televisão, imprensa em geral, literatura, cinema, fontes orais, monumentos, museus, canções etc.

\section{Considerações finais}

Nossa primeira consideração é que os espaços rurais e urbanos brasileiros investigados na região do Triângulo Mineiro, Minas Gerais, Brasil, se desenvolvem entre relações circulares, de profunda interdependência em vários aspectos. Os jovens estudantes investigados vivem, nas fendas, entre os dois mundos. São espaços de fronteira cada vez mais fluidos. Assim, é perceptível que as culturas perderam a relação exclusiva com seus territórios, ganharam em comunicação e conhecimento. Os espaços escolares pesquisados são multiculturais multifacetados, apresentam suas singularidades, mas profundamente marcados pela educação escolar e a cultura rurbana dos municípios. Nenhum dos 130 colaboradores possuía trabalho formal, porém muitos trabalhavam na 
informalidade. Podiam ser considerados jovens pobres. A renda familiar era menor entre os jovens estudantes das escolas localizadas no meio rural.

No que se refere à política, evidenciamos que os jovens urbanos acreditavam mais nas marcas da política em suas vidas; a maior parte dos jovens rurais declarou que não influenciam a política. Revelaram-se também mais descrentes em relações às instituições públicas. Foi recorrente a reafirmação, entre os jovens do meio rural e urbano, o papel da família como elemento aglutinador. Em relação aos direitos humanos e cidadania, prevaleceu o silêncio dos colaboradores, principalmente por parte dos jovens das escolas urbanas. Aqueles que se manifestaram, priorizaram os direitos individuais, em detrimento dos coletivos, o que reforça a importância da educação para a cidadania.

Dessa forma, defendemos que a finalidade da educação escolar obrigatória deve ser a educação para uma cultura democrática e participativa, ou seja, formar jovens estudantes para o compromisso social, para intervir na sociedade. Isso requer o desenvolvimento de propostas curriculares que valorize os problemas sociais atuais, latentes, historicamente relevantes. Assim, a questão da cidadania adquire sentido, pois parte da realidade, se focaliza nela e busca ações conscientes e responsáveis.

Os jovens estudantes são atores sociais plurais, caracterizados pelas diferenças sociais e pela diversidade cultural, que produzem impactos nos modos como vivem a condição juvenil e atribuem sentidos e significados ao mundo. Muitos, por um lado, expressaram não se sentirem contemplados pelas políticas públicas, por outro, revelaram a preocupação com o mundo onde vivem. Demonstraram acreditar que podiam mudar o mundo, defendiam a solidariedade para com o próximo e a importância de valorizar o meio ambiente. Como afirma Dayrell (2007), não podemos esquecer o óbvio: eles são jovens, amam, sofrem, divertem-se, pensam a respeito das suas condições e de suas experiências de vida, posicionam-se diante dela, possuem desejos e propostas de melhorias de vida.

Nesse cenário, um dos principais desafios do professor de História é o de contribuir para o alargamento e aprofundamento do campo de reflexão dos jovens estudantes em relação à política, direitos humanos e cidadania na formação de suas subjetividades. Concordamos com Martins (2011), ao afirmar que, de um modo geral, o ensino de História situa-se em uma dupla perspectiva: tradicional e potenciadora. A primeira de cunho mais restrito, na qual o professor se limita a "dar aulas de História", e a segunda, mais abrangente, que pode gerar efeito formador e conformador da consciência histórica dos jovens estudantes. A segunda pode contribuir para a formação cidadã crítica e participativa dos jovens estudantes. 
Consideramos basilar a contribuição da História na formação dos jovens estudantes, pois como disciplina formativa não só pode auxiliar no entendimento da própria realidade e na formação das identidades, mas também na compreensão da diferença, da alteridade, tanto para ensinar a convivência nas sociedades, que hoje são, na maioria, multiculturais, quanto para ensinar a julgar o próprio sistema político e social em que se vive. Como nos ensina Rusen (2010), a tarefa proposta para o ensino de História não se limita à formação de identidades, mas também ao de desenvolver o pensamento crítico.

Defendemos o papel político e cultural do ensino de História nas escolas. O diálogo entre os sujeitos (professores e alunos), os conhecimentos (conteúdos, e metodologias fundamentadas teoricamente tanto na historiografia quanto na pedagogia) e o mundo plural e diverso em que vivemos é fundamental no processo de aprender. Os jovens não têm apenas direito à escola, mas o direito de aprender. Por meio de um intenso e fértil compromisso dos protagonistas - alunos e professores -, podemos não apenas evitar uma prática de ensino de História dogmática e ideológica, mas fomentar uma prática criativa e formativa da consciência histórica dos jovens estudantes. Dessa forma, como propõe Pagès (2011), podemos caminhar para uma cidadania mundial.

\section{Referências}

ABRAMO, H. W.; BRANCO, P. P. M. Retratos da juventude brasileira. São Paulo: Instituto Cidadania; Fundação Perseu Abramo, 2005.

ALEGRO, R. C. Considerações acerca da experiência de elaboração e aplicação de manual para coleta e tratamento de relatos orais no ensino básico. In: CERRI, L. F. (Org.). Ensino de História e Educação: olhares em convergência. Ponta Grossa: UEPG, 2007. p. 11-25

ANDRÉ, M. Etnografia da prática escolar. Campinas: Papirus, 1995.

BAUMAN, Z. Modernidade líquida. Rio de Janeiro: Jorge Zahar, 2001.

Identidade. Rio de Janeiro: Jorge Zahar, 2005.

BITTTENCOURT, C. M. F. Ensino de História: fundamentos e métodos. São Paulo: Cortez, 2005.

BOGDAN, R. C.; BIKLEN, S. K. Investigação qualitativa em educação. Porto: Porto, 1991.

BRASIL. Constituição Federal de 1988. Disponível em: < http://www.planalto.gov.br>. Acesso em: 20 dez. 2005.

CANDAU, V. M. F. Sociedade, cotidiano escolar e cultura(s): uma aproximação. Educação \& Sociedade, Campinas, v. 23, n. 79, p. 125-161, ago. 2002. DOI: 10.1590/S010173302002000300008

CARNEIRO, M. J. Juventude rural: projetos e valores. In: ABRAMO, H. W.; BRANCO, P. P. M. Retratos da juventude brasileira. São Paulo: Instituto Cidadania; Fundação Perseu Abramo, 2005. p. 243-261 
CERRI, L. F. Ensino de História e consciência histórica. Rio de Janeiro: FGV, 2011.

DAYRELL, J. O jovem como sujeito social. Revista Brasileira de Educação, Rio de Janeiro, n. 24, p. 40-52, set./dez. 2003. DOI: 10.1590/S1413-24782003000300004

A escola "faz" as juventudes? Reflexões em torno da socialização juvenil. Educação

\& Sociedade, Campinas, v. 28, n. 100, Especial, p. 1105-1128, out. 2007. DOI: 10.1590/ S0101-73302007000300022

GEERTZ, C. A interpretação das culturas. Rio de Janeiro: Editora Zahar, 1978.

GINZBURG, C. Sinais: raízes de um paradigma indicário. In: GINZBURG, C. Mitos, emblemas, sinais. São Paulo: Companhia das Letras, 2007. p. 143-180.

GUIDO, H. Filosofia da educação: entre o anti-moderno e o ultra-moderno. In: HENZ, C. I.; ROSSATO, R. (Orgs.). Educação humanizadora na sociedade globalizada. Santa Maria: Biblos, 2007. p. 45-73.

HALL, S. A identidade cultural na pós-modernidade. Rio de Janeiro: DP\&A, 1999.

KRISCHKE, P. J. Questões sobre juventude, cultura política e participação democrática. In: ABRAMO, H. W.; BRANCO, P. P. M. (Orgs.). Retratos da juventude brasileira. São Paulo: Fundação Perseu Abramo, 2005. p. 323-350.

MARIN, J. O. B. A construção social da juventude rural. In: CONGRESO LATINOAMERICANO DE SOCIOLOGIA RURAL, 8., 2010, Porto de Galinhas. Anais... Porto de Galinhas: ALASRU, 2010. p. 1-20.

MARTINS E. C. de R. A exemplaridade da História: prática e vivência do ensino. In: FONSECA, S. G.; GATTI JÚNIOR, D. (Orgs.). Perspectiva do Ensino de História: ensino, cidadania e consciência histórica. Uberlândia: Edufu, 2011. p. 83-92.

MODESTO, A. L. Religião, escola e os problemas da sociedade contemporânea. In: DAYRELL, J. (Org.). Múltiplos olhares sobre educação e cultura. Belo Horizonte: UFMG, 1996. p. 77-84.

NOVAES, R. Juventude, percepções e comportamentos: a religião faz diferença? In: ABRAMO, H. W.; BRANCO, P. P. M. (Orgs.). Retratos da juventude brasileira. São Paulo: Fundação Perseu Abramo, 2005. p. 263-290.

Os jovens de hoje: contextos, diferenças e trajetórias. In: ALMEIDA, M. I. M. de; EUGENIO, F. (Orgs.). Culturas jovens: novos mapas do afeto. Rio de Janeiro: Jorge Zahar, 2006. p. 105-120.

PAGÈS, J. Educación, ciudadanía y enseñanza de la História. In: FONSECA, S. G.; GATTI JÚNIOR, D. (Orgs.). Perspectivas do ensino de História: ensino, cidadania e consciência histórica. Uberlândia: Edufu, 2011. p. 17-31.

PAIS, J. M. Consciência histórica e identidades: os jovens portugueses num contexto Europeu. Celta, 1999.

PORTINARI, D.; COUTINHO, F. R. A roupa faz o homem: a moda como questão. In: ALMEIDA, M. I. M. de; EUGENIO, F. (Orgs.). Culturas jovens: novos mapas do afeto. Rio de Janeiro: Jorge Zahar, 2006. p. 59-76 
RUSEN, J. Razão histórica - teoria da História: fundamentos da ciência história. Brasília: Universidade Brasília, 2001.

História viva: teoria da História: formas e funções do conhecimento histórico. Brasília: Universidade de Brasília, 2007.

O livro didático ideal. In: SCHIMITDT, M. A.; BARCA, I.; MARTINS, E. de R. Jorn Rusen e o ensino de História. Curitiba: UFPR, 2010. p. 109-127.

SACRISTÁN, G. J. Currículo e diversidade cultural. In: SILVA, T. T. MOREIRA, A. F. (Orgs.). Territórios contestados: o currículo e os novos mapas políticos e culturais. Petrópolis: Vozes, 1995. p. 85-102

SANTISTEBAN, A. F.; PAGÈS, J. La educación democrática de la ciudadania: uma propuesta conceptual. In: AVILA, R. M.; LOPEZ, M.; FERNÁNDEZ, E. (Eds.). Las conpetencias profesionales para la enseñanza-aprendizaje de las Ciencias Sociales ante el reto europeo y la globalización. Bilbao: Asociación Universitaria del Profesorado de Didáctica de las Ciencias Sociales, 2007. p. 353-367.

SCHMIDT, M. A.; BARCA, I.; GARCIA, T. B. Significados do pensamento de Jorn Rusen para investigações na área da educação histórica. In: SCHIMIDT, M. A.; BARCA, I.; MARTINS, E. de R. (Orgs.). Jorn Rusen e o ensino de História. Curitiba: UFPR, 2010. p. 11-21.

SILVA BLASS, L. M. da. Juventude e trabalho. In: COSTA, M. R.; SILVA, E. M. da. (Orgs.). Sociabilidade juvenil e cultura urbana. São Paulo: Educ, 2006. p. 55-77

SILVA, M.; FONSECA, S. G. Ensinar História no século XXI: em busca do tempo entendido. Campinas: Papirus, 2007.

Ensino de História hoje: errâncias, conquistas e perdas. Revista Brasileira de História, São Paulo, v. 31, n. 60, p. 13-33, 2010. DOI: 10.1590/S0102-01882010000200002

SINGER, P. A juventude como coorte: uma geração em tempos de crise social. In: ABRAMO, H. W.; BRANCO, P. P. M. (Orgs.). Retratos da juventude brasileira. São Paulo: Fundação Perseu Abramo, 2005. p. 27-35.

SPOSITO, M. P. Estudos sobre Juventude e Escolarização. Revista Brasileira de Educação, São Paulo, n. 5/6, p. 37-52, maio/dez. 1997.

WANDERLEY, M. de N. B. A sociologia rural na América Latina: produção de conhecimento e compromisso com a sociedade. Revista ALASRU, Nueva Época, n. 5, p. 17-44, 2010.

Recebido em 03/04/2012

Versão final recebida em 30/09/2012

Aceito em 02/10/2012 